\title{
Selection for encoding: No evidence of greater attentional capture following forget than remember instructions
}

\author{
Tracy L. Taylor ${ }^{1}$ • Jeff P. Hamm ${ }^{2}$
}

Published online: 24 September 2015

(C) The Psychonomic Society, Inc. 2015

\begin{abstract}
We measured attentional orienting in an itemmethod-directed forgetting task. Words appeared singly, followed by an instruction to remember or forget. In Experiment 1, study words appeared at center; in Experiments 2 and 3 , they appeared to the left and right. In all three experiments, there was a delay of $50 \mathrm{~ms}$ or $250 \mathrm{~ms}$, after which a cue appeared to the left or right of fixation. This was followed at a fixed 100-ms stimulus onset asynchrony by a target in the cued or uncued location. Attentional capture was measured by evaluating the speed to localize (Experiments 1 and 2) or discriminate (Experiment 3 ) targets in cued versus uncued locations. A subsequent yes-no recognition test confirmed a directed forgetting effect. Even though attention is purported to withdraw more readily after forget instructions than after remember instructions, we obtained no evidence for the corollary: Attention is not more readily captured by events that follow forget instructions. A forget instruction must therefore impact attention only insofar as withdrawal is needed to instantiate the intention to forget, without instigating a longer lasting distractibility.
\end{abstract}

Keywords Attention: Interactions with memory $\cdot$ Attention and memory $\cdot$ Attention $\cdot$ Directed forgetting $\cdot$ Intentional forgetting

Intentional forgetting occurs when top-down control mechanisms are engaged to prevent the encoding and/or retrieval of

Tracy L. Taylor

ttaylor2@Dal.ca

1 Department of Psychology and Neuroscience, Dalhousie University, 15000, 1355 Oxford Street, Halifax, Nova Scotia B3H 4R2, Canada

2 School of Psychology, The University of Auckland, Auckland, New Zealand unwanted items. Whereas unintentional forgetting reflects a failure of memory, intentional forgetting is an adaptive mechanism that enables control over the contents of memory (Anderson, 2003; Anderson \& Huddleston, 2012; Bjork, 1989). When performed at encoding, intentional forgetting ensures that limited-capacity attentional mechanisms are protected from distraction and able to focus on goal-relevant inputs (cf. Kuhl, Dudukovic, Kahn, \& Wagner, 2007).

In the laboratory, an item-method directed forgetting task is used to study top-down control over encoding. Participants are presented with study items one at a time, each followed with equal probability by an instruction to remember or forget. Because the instruction occurs after the disappearance of each study item (although see e.g., Paller, 1990), participants must attend to each in turn and maintain the item representation in working memory until the instruction is presented (Gardiner, Gawlik, \& Richardson-Klavehn, 1994; Hsieh, Hung, Tzeng, Lee, \& Cheng, 2009). If the instruction is to remember the item, participants engage in elaborative rehearsal to commit the item to memory. However, if the instruction is to forget the item, participants engage active cognitive control (Cheng, Liu, Lee, Hung, \& Tzeng, 2012; Fawcett \& Taylor, 2008; Lee \& Hsu, 2013; Ludowig, Möller, Bien, Münte, Elger, \& Rosburg, 2010; see also Fawcett, Taylor, \& Nadel, 2013a) to withdraw attention from the item representation (Fawcett \& Taylor, 2010; Taylor, 2005; Taylor \& Fawcett, 2011; Thompson, Hamm, \& Taylor, 2014; see also Rizio \& Dennis, 2013), which - in the case of visually presented items - includes not only semantic information (e.g., Lin, Kuo, Liu, Han, \& Cheng, 2013) but also information about spatial location (e.g., Hourihan, Goldberg, \& Taylor, 2007) as well as other perceptual features (Lee, Lee, \& Fawcett, 2013). This withdrawal of processing resources from forget-item representations is achieved through the activation of frontal control mechanisms (Rizio \& Dennis, 2013; van Hooff \& Ford, 2011; Wylie, Foxe, 
\& Taylor, 2008; Yang, Liu, Xiao, Li, Zeng, Qiu, \& Zhang, 2012) that limit further covert rehearsal of the unwanted memory traces (Hourihan \& Taylor, 2006), even if they do not prevent further encoding entirely (Lee, Lee, \& Tsai, 2007). Intentional forgetting at encoding is therefore accomplished by activating mechanisms that are analogous to (Hourihan \& Taylor, 2006) - even if not identical with (Fawcett \& Taylor, 2010) - those that are engaged top-down to prevent the execution of unwanted overt motor responses (e.g., Aron, Fletcher, Bullmore, Sahakian, \& Robbins, 2003; see Verbruggen \& Logan, 2008 for a review). As a result, forget-instructed items receive less rehearsal than remember-instructed items (i.e., selective rehearsal; e.g., Basden, 1996; Basden, Basden, \& Gargano, 1993; Bjork, 1970; Johnson, 1994), such that both the probability and the fidelity of later retrieval from long-term memory is reduced (Fawcett, Lawrence, \& Taylor, submitted; see also Fawcett, Taylor, \& Nadel, 2013a, b).

The influence of memory instruction specifically on the probability of subsequent retrieval is revealed by a directed forgetting effect, which is defined as better memory for remember-instructed items (hereafter: remember items) than for forget-instructed items (hereafter: forget items) (see MacLeod, 1998, for a review). The magnitude of the directed forgetting effect is related to cognitive load, such that the success of instantiating instructions to forget is increased under conditions of high load (Lee, 2012; Lee \& Lee, 2011). This suggests that competition for limited-capacity attentional resources is the driving force behind the active withdrawal of attention from forget-item representations in working memory. The reasoning is that participants are most likely to engage in the cognitively effortful withdrawal of attention when limited-capacity resources are under pressure and need to be freed for other goal-relevant activity. The immediate consequence of attentional withdrawal is reduced encoding of the now task-irrelevant forget item as well as of other items presented in close temporal and/or spatial proximity (e.g., Fawcett \& Taylor, 2008, 2012; Lee \& Hsu, 2013).

Given that attention withdraws more readily following forget instructions than following remember instructions, our goal was to test the corollary: that in the moments following a forget instruction, attention is withdrawn from the item representation and becomes momentarily free to be captured by new events that occur in the environment. To assess this, we measured attentional orienting to a spatially non-predictive peripheral onset cue that followed an auditory instruction to either remember or forget a preceding word. This kind of cue is intended to capture exogenous attention to the cued location (e.g., Jonides, 1981; Jonides \& Yantis, 1988; Yantis \& Jonides, 1984). We elected to test the capture of exogenous attention - rather than endogenous attention - because the latter requires top-down processing that is likely to interact with the top-down processing required to instantiate the memory instructions. Moreover, it is specifically exogenous attention rather than endogenous attention that is differentially withdrawn from forget words and remember words (Taylor \& Fawcett, 2011).

The allocation of exogenous attention is typically measured by presenting participants with a spatially non-predictive onset cue in the visual periphery, followed by a visual target that requires a speeded manual key-press response (e.g., Jonides \& Yantis, 1988; Posner, 1980; Yantis \& Jonides, 1984). The rationale is that attention enhances perceptual processing for stimuli that appear at its locus (e.g., Hawkins, Hillyard, Luck, Mouloua, Downing, \& Woodward, 1990; Hopfinger \& Mangun, 1998, 2001). Thus, if an onset cue captures attention despite being non-predictive of the impending target location, this will be revealed by faster reaction times (RTs) to targets that appear in the cued location than to targets that appear in the uncued location. This difference in RTs to cued and uncued targets defines a cueing effect and indexes the effectiveness of the cue in capturing exogenous attention, with larger cueing effects indicating more effective capture.

To measure attention in an item-method directed forgetting paradigm, we presented study words one at a time. Each was followed with equal probability by a tone that served as the instruction to remember or forget the preceding word. Following this memory instruction, we presented an onset cue that appeared with equal probability to the left or right. Given that we could not know a priori how long it might take to instantiate the memory instruction and free exogenous attention for capture, we presented this cue following either a relatively short (50-ms) or a relatively long (250-ms) inter-stimulus interval (ISI) relative to the instruction. The cue was intended to capture exogenous attention and its effectiveness in doing so was determined by measuring the cueing effect to the targets. We fixed the cue-target stimulus onset asynchrony at $100 \mathrm{~ms}$ to ensure that the targets were presented within a temporal window capable of measuring exogenous attentional orienting (e.g., Müller \& Rabbitt, 1989). If attention is more readily captured following forget instructions than following remember instructions, this will be revealed as an interaction between memory instruction and cueing effects, with larger cueing effects on forget trials than on remember trials.

\section{Experiment 1}

In Experiment 1, we presented study words at center to avoid contamination of the peripheral locations by the word onset. We used a target localization response to assess attentional orienting because, unlike a detection task, localization does not require the use of catch trials and, unlike a discrimination task, localization does not impose an arbitrary stimulus-response mapping to potentially compete with the participants' goal of committing the remember words to memory. 


\section{Method}

\section{Participants}

Data were initially contributed by 46 undergraduate students from Dalhousie University who participated in exchange for credit toward an introductory psychology course. Five of these participants were replaced with new participants because they revealed that they had taken part in previous studies of directed forgetting and/or self-reported a failure to follow the task instructions; none of these culled data sets were analyzed or evaluated prior to or following replacement. The final data were contributed by 41 of the original participants and the five replacement participants, for a total sample size of 46. All participants were tested individually in a session that lasted no more than $1 \mathrm{~h}$.

This research protocol was determined by the Dalhousie Social Sciences and Research Ethics Board to comply with the Canadian Tri-council Policy on Ethical Conduct for Research with Human Participants.

\section{Stimuli and apparatus}

Stimulus presentation and response collection were controlled by Psyscope 1.5.2 (Cohen, MacWhinney, Flatt, \& Provost, 1993) running on 24-in Macintosh iMac computers equipped with Apple Universal Serial Bus QWERTY keyboards.

A list of 320 nouns was created using the on-line version of the MRC Psycholinguistic Database (http://websites. psychology.uwa.edu.au/school/MRCDatabase/uwa_mrchtm; Coltheart, 1981; Wilson, 1988). The words on this list had a mean Kucera-Francis (cf. Kucera \& Francis, 1967) word frequency of $52.26(R=1-787)$; concreteness rating of $578(R=$ 500-670); familiarity rating of $552.35(R=501-646) ; 1.31(R$ $=1-3)$ syllables; and $4.73(R=3-7)$ letters. Prior to testing each participant, custom software was used to randomly distribute ten words to each of 16 study lists and 160 words to a recognition foil list. This ensured a unique list composition for each participant. Each of the 16 study lists was used in one cell of the full experimental design, which was conceptualized as a 2 (Memory Instruction: Remember, Forget) $\times 2$ (InstructionCue ISI: Short $=50 \mathrm{~ms}$, Long $=250 \mathrm{~ms}) \times 2$ (Cue Location: Left, Right) $\times 2$ (Target Location: Left, Right) within-subjects factorial. The words on the foil list were presented only on the final recognition test.

During the study phase, three outline black boxes were displayed across the horizontal meridian of the computer monitor; using the Psyscope tools, these were drawn with a 1-point line and were set to 175 points wide and 100 points tall. On the monitors used for the experiment and at a viewing distance of $57 \mathrm{~cm}$, these rectangular boxes were $4.8^{\circ}$ of visual angle wide and $3.5^{\circ}$ of visual angle high. The middle box was centered on the computer monitor; the left and right boxes were separated from the middle box by $10.4^{\circ}$ of visual angle measured centerto-center.

All stimuli were presented on a uniform white background. The default Psyscope font was used for all text stimuli. Text attributes were set to black 24-point regular face with three exceptions: titles were presented in boldface; the recognition instructions were presented in 16-point font; and, a fixation stimulus consisting of black crosshairs ("+") changed to green or red to communicate correct and incorrect target responses, respectively. The memory instruction was a high-frequency tone $(1170 \mathrm{~Hz})$ or a low-frequency tone $(260 \mathrm{~Hz})$ played over both channels of Sony MDR-XD100 headphones. The cue consisted of four colons separated by two spaces (":: ::"); the target consisted of a small letter "o" flanked by two spaces on either side (" o "). The fixation stimulus, study words, cues, and targets were all centered in the stimulus box in which they were presented. Study and recognition words were presented in all lowercase letters.

\section{Procedure}

Prior to beginning the experiment, participants received both a verbal and written overview of the experiment and provided written informed consent. They were then presented with tone familiarization trials, target practice trials, study trials, and recognition trials. Before all but the recognition trials, written instructions were presented on the computer monitor to inform participants of the nature of the upcoming task and to describe/ depict the trial events. In each case, participants were invited to call the experimenter back into the room if they had any questions; none exercised this option. Participants depressed the space bar to proceed from the instructions to the relevant trials. For the recognition task, instructions were not presented on a separate splash page preceding the trials but instead remained visible at the top of the computer monitor during all trials.

Tone familiarization trials Prior to beginning the experimental trials, participants received ten tone familiarization trials. For half of the participants, the high tone served as the Remember instruction and the low tone as the Forget instruction; this designation was reversed for the other half of the participants. Each of the tone familiarization trials started with a $500-\mathrm{ms}$ presentation of the fixation crosshairs ("+") in the center of an otherwise uniform white field. This fixation stimulus was replaced by a $1,000-\mathrm{ms}$ presentation of a written descriptor of the memory instruction (e.g., "Low Tone - FORGET"), halfway through which the relevant tone sounded for $500 \mathrm{~ms}$. This was followed by a 1,000-ms inter-trial interval (ITI) during which the computer monitor remained blank. 
Target practice trials Following the tone familiarization trials, participants were given practice making speeded responses to the targets, without the concurrent task of committing words to memory. Participants were asked to rest their left and right index fingers on the " $\mathrm{f}$ " and " $\mathrm{j}$ " keys, respectively, and to use these keys to make spatially compatible responses to left and right targets, as quickly and as accurately as possible. There was a total of 16 practice trials drawn randomly from the full experimental design. These were identical to study trials in every way except that the string "word" was presented on every trial instead of a study item and there was no requirement to commit this string to memory (note that "word" was not an item on the word list used in the experiment proper).

Study trials Following the target practice trials, participants were instructed that the study trials would follow. They were told that a different word would be presented on every trial, each followed by an instruction to Remember or Forget; they were reminded of the meaning of the high and low tones. Participants were told that they should try to commit all of the Remember words to memory for a later test but that they could forget the Forget words; no mention was made of the fact that assessing their ability to follow these instructions would require testing subsequent recognition of both Remember words and Forget words.

As depicted in Fig. 1, each study trial started with a 2,000ms delay during which only the three stimulus boxes were visible on the computer monitor. Except for the first trial, this delay contributed to the ITI and was intended to provide a non-distracting visual display that participants could view while awaiting the next trial. The black fixation crosshairs ("+") then appeared in the center of the middle box for $500 \mathrm{~ms}$ before being replaced by a word for $400 \mathrm{~ms}$, and then reappearing for the remainder of the trial. Immediately after the disappearance of this word, a high or a low tone was played with equal probability for $400 \mathrm{~ms}$ over the headphones. On a random half of the trials, there was a 50-ms ISI between the offset of the memory instruction and the onset of the cue; on the other half of the trials this ISI was $250 \mathrm{~ms}$. The cue stimulus appeared with equal probability in the right or the left stimulus box and remained visible for $100 \mathrm{~ms}$. The target appeared immediately afterward, at a $100-\mathrm{ms}$ stimulus onset asynchrony (SOA), and remained visible for $100 \mathrm{~ms}$. Participants were required to respond to the target within $1,500 \mathrm{~ms}$ of its onset. If they localized the target correctly within this time window, the fixation stimulus changed from black to green for $500 \mathrm{~ms}$; if they pressed the wrong response key, the fixation stimulus changed from black to red for $500 \mathrm{~ms}$; if they failed to make a response with the " $\mathrm{f}$ " or " $\mathrm{j}$ " key within 1,500 ms of target onset, the monitor cleared and a question mark ("?") appeared in the center of the computer screen for $500 \mathrm{~ms}$.
There was a total of 160 study trials, divided equally and randomly intermixed over all 16 cells of the fully factorial design (as described above). For the purpose of subsequent analyses, the cue location and target location factors were collapsed into a single factor called Cueing Condition, such that cues and targets in the same location (i.e., Left-Left, Right-Right) comprised the Cued condition whereas cues and targets in different locations (i.e., Left-Right, Right-Left) comprised the Uncued condition. Thus, our design was recast as a 2 (Memory Instruction: Remember, Forget) $\times 2$ (Instruction-Cue ISI: Short $=50 \mathrm{~ms}$, Long $=250 \mathrm{~ms}) \times 2($ Cueing Condition: Cued, Uncued) design.

Recognition trials The recognition trials followed immediately after the last of the study trials. The title "Recognition Memory Test" appeared at the top center of the computer monitor and instructions were presented in the top one-third of the computer monitor; both remained visible throughout the trials. These instructions informed participants that they were to try to recognize all words presented during the study trials, regardless of the associated memory instruction. They were instructed to press " $y$ " (yes) to indicate words that they recognized from the study trials and " $n$ " (no) to indicate words that they did not recognize.

Test words were presented one at a time below the task instructions. Below each recognition word was the prompt: "Do you recognize this word? (y/n):". Keyboard strokes were echoed to the screen; they appeared to the right of this prompt and could be self-corrected using the backspace key until the trial was advanced by pressing the "return" key. The $80 \mathrm{Re}-$ member words and 80 Forget words from the study trials were intermixed randomly with 160 unstudied Foil words, for a total of 320 recognition trials. Recognition hits were defined as " $y$ " responses to Remember words and Forget words; false alarms were defined as "y" responses to Foil words.

Data analysis All data cleaning and analyses were conducted using R Studio 0.98.1078 running R 3.1.2 (R Core Team, 2014). Various $R$ packages were used to clean the data, including plyr (Wickham, 2011), dplyr (Wickham \& Francois, 2014), tidyr (Wickham, 2014), and stringr (Wickham, 2012). The R package ez 4.2-2 (Lawrence, 2013) was used to calculate descriptive statistics (ezStats) and within-subjects analyses of variance (ezANOVA), and to create plots (ezPlot) that were subsequently modified using ggplot2 (Wickham, 2009).

The output from ezANOVA was used to generate a Bayesian Information Criterion (BIC) approximation to Bayesian posterior probabilities according to the method described by Masson (2011). This was accomplished by implementing in $\mathrm{R}$ the formulae contained in the spreadsheet that Masson provided as supplementary material. We will use the convention $p \mathrm{H} 1$ to refer to the approximated posterior probability of the alternative (i.e., non-zero effect) given the data and $p \mathrm{H} 0$ to refer to 
Study Trials

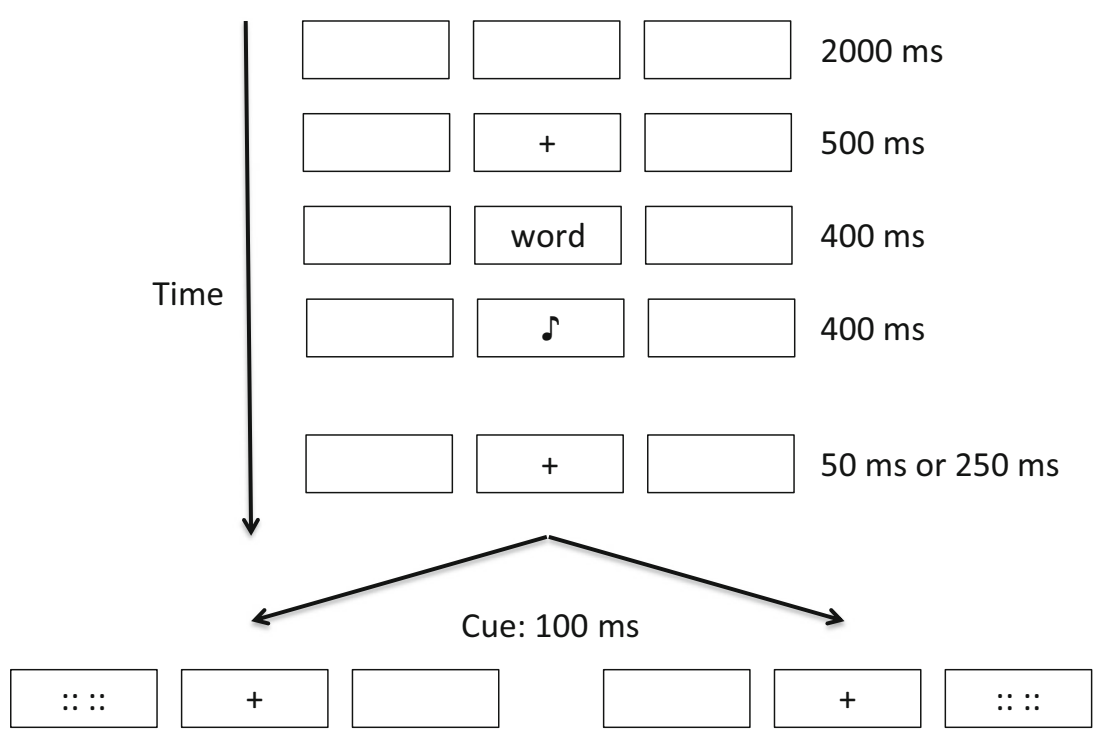

Target: $100 \mathrm{~ms}$
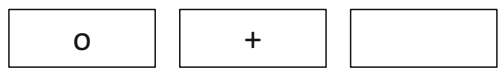

Cued
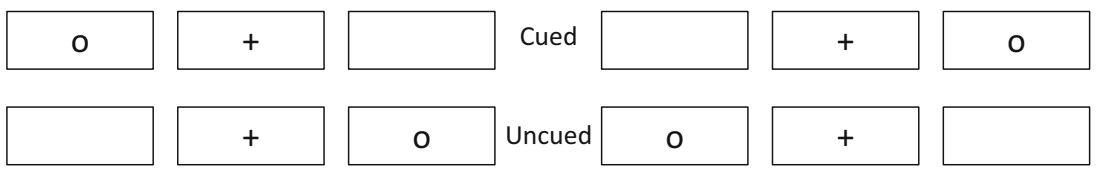

o

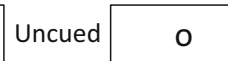

$+$

Fig. 1 Schematic representation of the study trials in Experiment 1. See text for a detailed description of the study phase events

the approximated posterior probability of a null effect given the data. Given that the values of $p \mathrm{H} 0$ and $p \mathrm{H} 1$ sum to 1 , we will report only the larger of the two values. In doing so, we will apply verbal descriptors using the conventions suggested by Raftery (1995; as cited in Masson, 2011): 0.50-0.75 = "weak," 0.75-0.95 = "positive," 0.95-0.99 = "strong," >0.99 $=$ "very strong." Although we interpret our results in terms of these estimated posterior probabilities, to assist readers who are unaccustomed to this data analytic technique, we also provide the F-test statistics and include generalized eta squared (ges) as a measure of effect size.

In an initial pass through the data, we calculated mean proportion Foil false alarm rates (i.e., "yes" responses) for each participant on the recognition test. If a participant's Foil false alarm rate exceeded the mean of all participants by more than 2 standard deviations (SDs), the data contributed by that participant were excluded from all subsequent analyses. We also examined trial-by-trial target RTs on study trials and eliminated as errors those trials on which the incorrect response key was pressed, on which no key press was detected, or for which the RT was faster than $100 \mathrm{~ms}$ or slower than $1,500 \mathrm{~ms}$. We removed from all analyses the data from any participant whose average target accuracy was more than two SDs below the mean target accuracy of all participants.

Following these exclusions, trial-by-trial data (rather than collapsed condition means) were used to calculate descriptive statistics (ezStats) and inferential statistics (ezANOVA) and to plot the results (ezPlot), with the full design specified as a parameter in the relevant ez function (see Lawrence, 2013).

\section{Results}

Three participants had average Foil false alarm rates that were more than 2 SDs higher than the mean of all participants; data contributed by these participants were removed from all subsequent analyses. There were no data sets excluded based on average target accuracies. The following reports the analyses based on the remaining 43 datasets.

\section{Recognition trials}

In the recognition test, there was a mean proportion of 0.61 "yes" responses to Remember words, 0.22 to Forget words, and 0.07 to unstudied Foil words. A one-way ANOVA with Word Type (Remember, Forget, Foil) as the repeated measure revealed very strong evidence of an effect, $F(2,84)=308.56$, $M S e=0.01, p<0.01$, ges $=0.78, p \mathrm{H} 1>0.99$. A comparison of recognition hits on Remember and Forget trials provided very strong support for a directed forgetting effect, $F(1,42)=$ $249.08, M S e=0.01, p<0.01$, ges $=0.65, p \mathrm{H} 1>0.99$. There was very strong evidence of more hits to Remember words than false alarms to Foil words, $F(1,42)=411.66, M S e=0.02$, 
$p<0.01$, ges $=0.83, p \mathrm{H} 1>0.99$, and more hits to Forget words than false alarms to Foil words, $F(1,42)=118.75$, $M S e=0.004, p<0.01$, ges $=0.39, p \mathrm{H} 1>0.99$.

These data confirmed that participants used the memory instructions during encoding to commit to memory more Remember words than Forget words.

\section{Study trials}

Mean RTs were calculated for correct target localization responses made within 100-1,500 ms of target onset. Across all 43 participants, only two trial RTs were excluded for being too fast; all other exclusions were based on incorrect key presses. The proportions of retained (correct) trials are shown in Table 1.

Target RTs The mean RTs for correct trials are shown in Fig. 2. These data were analyzed as a function of Memory Instruction (Remember, Forget), Instruction-Cue ISI (Short = $50 \mathrm{~ms}$, Long $=250 \mathrm{~ms}$ ), and Cueing Condition (Cued, Uncued). This analysis provided positive evidence against a difference in RTs on Remember and Forget trials, $F(1,42)<1$, $M S e=3599.01, p>0.74$, ges $<0.01, p \mathrm{H} 0=0.86$. There was very strong evidence of faster RTs on trials with long Instruction-Cue ISIs, compared to trials with short Instruction-Cue ISIs, $F(1,42)=27.11, M S e=2220.56, p<$ 0.01 , ges $=0.02, p \mathrm{H} 1>0.99$. This pattern is consistent with increasing alertness due to decreasing temporal uncertainty (see Nobre, Correa, \& Coull, 2007 for a review). There was also very strong evidence of overall faster RTs to Cued targets $(M=459 \mathrm{~ms})$ than to Uncued targets $(M=537 \mathrm{~ms}), F(1,42)=$ 78.76, $M S e=6210.45, p<0.01$, ges $=0.14, p H 1>0.99$. This cueing effect demonstrates the efficacy of the onset cues in capturing attention to the peripheral locations.

There was positive evidence against an interaction between Memory Instruction and Instruction-Cue ISI, $F(1,42)<1$, $M S e=1899.76, p>0.46, p \mathrm{H} 0=0.83$. There was, however, positive evidence in favor of the critical interaction between
Memory Instruction and Cueing Condition, $F(1,42)=9.60$, $M S e=1443.79, p<0.01$, ges $<0.01, p H 1=0.93$. But, as shown in Fig. 2, this interaction was not in the predicted direction: the cueing effect following Forget instructions $(M=63$ $\mathrm{ms}$ ) was smaller - not larger - than the cueing effect following Remember instructions $(M=93 \mathrm{~ms})$. There was weak evidence against an interaction between Instruction-Cue ISI and Cueing Condition, $F(1,42)=3.77, M S e=2521.39, p>0.05$, ges $<0.01, p \mathrm{H} 0=0.51$, and positive evidence against a threeway interaction between Memory Instruction, Instruction-Cue ISI, and Cueing Condition, $F(1,42)<1, M S e=1714.26, p>$ 0.78 , ges $<0.01, p \mathrm{H} 0=0.86$. The lack of evidence for a threeway interaction indicates that differences in cueing effects on Forget and Remember trials were not influenced by the amount of time available to process those instructions.

Target accuracies We applied the same analytic strategy to the accuracy data summarized in Table 1 . There was positive evidence against effects of Memory Instruction, $F<1$, MSe $<$ $0.01, p>0.98$, ges $<0.01, p \mathrm{H} 0=0.87$, and only weak evidence for an effect of Instruction-Cue ISI, $F(1,42)=5.56, M S e<0.01$, $p<0.03$, ges $=0.01, p \mathrm{H} 1=0.69$. There was, however, very strong evidence in favor of an effect of Cueing Condition, $F(1$, $42)=67.09, \mathrm{MSe}=0.02, p<0.01$, ges $=0.29, p \mathrm{H} 1>0.99$. Accuracy was overall higher to Cued targets $(M=0.98)$ than to Uncued targets $(M=0.87)$. This result counters a speedaccuracy trade-off, given that responses were both faster and more accurate to Cued targets than to Uncued targets.

There was positive evidence against an interaction between Memory Instruction and Instruction-Cue ISI, $F(1,42)<1$, MSe $<0.01, p>0.59$, ges $<0.01, p \mathrm{H} 0=0.85$, and against an interaction between Memory Instruction and Cueing Condition, $F(1,42)<1, M S e<0.01, p>0.96$, ges $<0.01, p \mathrm{H} 0=$ 0.87 . There was weak evidence in favor of an interaction between Instruction-Cue ISI and Cueing Condition, $F(1,42)=$ 3.93, MSe $<0.01, p>0.05$, ges $<0.01, p \mathrm{H} 1=0.51$. The cueing effect in accuracy (i.e., difference in accuracy to Cued versus Uncued targets) was 0.13 at the long Instruction-Cue ISI and

Table 1 Mean proportions of correct target responses in Experiments 1-3, as a function of Memory Instruction (Remember, Forget), Instruction-Cue inter-stimulus interval (Short $=50 \mathrm{~ms}$, Long $=250 \mathrm{~ms}$ ), and Cueing Condition (Cued, Uncued). The standard error of the mean is shown in parentheses

\begin{tabular}{|c|c|c|c|c|c|}
\hline \multirow[t]{2}{*}{ Experiment } & \multirow[t]{2}{*}{ Instruction } & \multicolumn{2}{|l|}{ Short } & \multicolumn{2}{|l|}{ Long } \\
\hline & & Cued & Uncued & Cued & Uncued \\
\hline \multirow[t]{2}{*}{ 1: Central words, Localization } & Remember & $0.98(0.006)$ & $0.89(0.018)$ & $0.98(0.006)$ & $0.85(0.020)$ \\
\hline & Forget & $0.99(0.005)$ & $0.88(0.019)$ & $0.98(0.006)$ & $0.86(0.020)$ \\
\hline \multirow[t]{2}{*}{ 2: Peripheral words, Localization } & Remember & $0.98(0.004)$ & $0.92(0.012)$ & $0.98(0.006)$ & $0.92(0.012)$ \\
\hline & Forget & $0.99(0.003)$ & $0.92(0.012)$ & $0.99(0.004)$ & $0.91(0.015)$ \\
\hline \multirow[t]{2}{*}{ 3: Peripheral words, Discrimination } & Remember & $0.77(0.021)$ & $0.71(0.027)$ & $0.76(0.025)$ & $0.72(0.019)$ \\
\hline & Forget & $0.81(0.019)$ & $0.75(0.020)$ & $0.77(0.022)$ & $0.71(0.024)$ \\
\hline
\end{tabular}




\section{Experiment 1: Centre Word, Localization}

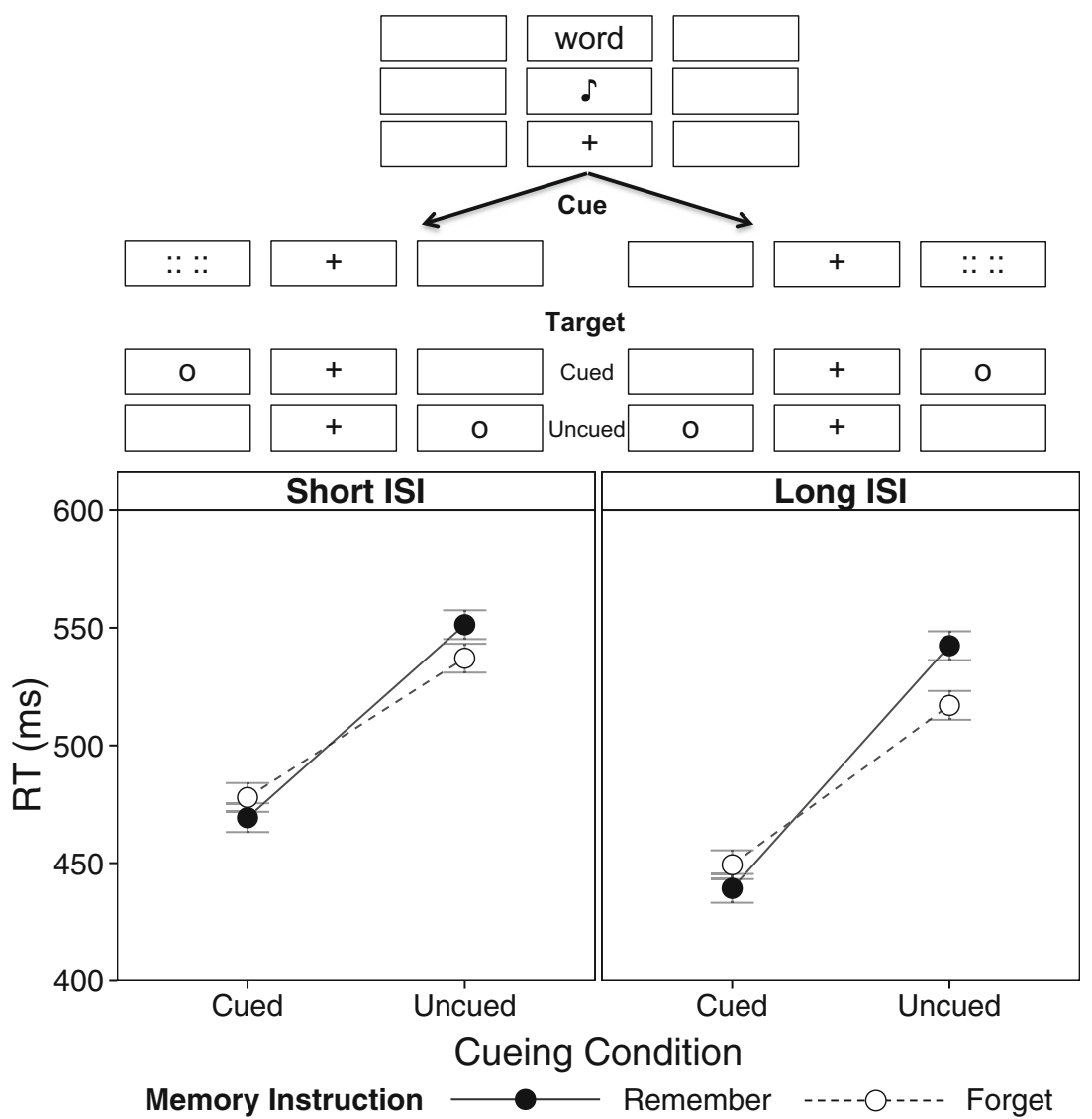

Fig. 2 RTs from the study trials of Experiment 1. The top panel depicts the trial events. The bottom panel shows the mean correct RTs (ms) to localize the target as a function of memory instruction (Remember, Forget) and Cueing Condition (Cued, Uncued), separated according to whether the inter-stimulus interval between the Memory Instruction and

0.10 at the short ISI, countering a speed-accuracy trade-off. There was positive evidence against a 3-way interaction between Memory Instruction, ISI, and Cueing Condition, $F(1$, $42)=1.38, \mathrm{MSe}<0.01, p>0.24$, ges $<0.01, p \mathrm{H} 0=0.77$.

\section{Discussion}

Performance in the yes-no recognition test provided very strong evidence of a directed forgetting effect, confirming that participants successfully instantiated the instructions to remember and forget. Notably, the magnitude of the directed forgetting effect was quite large, even when compared to other dual-task paradigms that measured recognition memory following a combined target task and unemotional word encoding task: our directed forgetting effect was 0.39 , which is at the high end of our similar published studies, which vary from $\sim 0.12$ 0.40 (e.g., Fawcett \& Taylor, 2008, 2010, 2012; Taylor, 2005; Taylor \& Fawcett, 2011; Thompson et al., 2014). An informal evaluation suggests that this was due to especially effective implementation of the forget instruction in the current
Cue was relatively Short (50 ms, left panel) or Long ( $250 \mathrm{~ms}$, right panel). To facilitate post-hoc visual comparisons, the error bars represent Fisher's Least Significant Difference on the three-way interaction; nonoverlapping bars can be interpreted as being significantly different

experiment: our obtained hit rate of 0.61 for remember items was consistent with other studies from our laboratory (range $\sim 0.46-0.74$ ), whereas our obtained hit rate of 0.22 for forget items was smaller than and outside of our typical range (range $\sim 0.31-0.54$ ). We would argue that the shorter interval between the word and target on the study trials (needed to measure exogenous orienting) likely made the current experiment more difficult for our participants than otherwise similar dual-task paradigms that presented a longer interval. Indeed, when we examined remember and forget trial performance as a function of word-target interval across similar dual-task studies (e.g., Fawcett \& Taylor, 2008, 2010, 2012; Taylor, 2005; Taylor \& Fawcett, 2011; Thompson et al., 2014), we obtained an $\mathrm{R}^{2}=$ 0.02 for remember items and $\mathrm{R}^{2}=0.47$ for forget items (neither of which was attributable to outliers).

Our pattern of remember and forget trial recognition performance is thus consistent with the pattern across other published studies and in support of the hypothesis that instructions to forget are implemented most effectively when the cognitive system is taxed (Lee \& Lee, 2011; Lee, 2012). This 
observation bolsters the supposition that competition for limited-capacity resources triggers the differential withdrawal of attention from the representation of forget words and remember words. Indeed, this characterization informed our critical question about whether instructions to remember versus forget would modulate the size of the attentional cueing effects measured by the difference in RTs to respond to cued and uncued targets.

Our analysis of target RTs did, in fact, provide positive evidence of a two-way interaction between memory instruction and attentional cueing. However, this critical interaction was in the direction opposite to that which we predicted: cueing effects were smaller, not larger, following forget instructions than following remember instructions. This result was unexpected and indicates that attentional capture was relatively decreased following forget instructions in Experiment 1, rather than increased. Positive evidence against the 3-way interaction indicates that this pattern was relatively stable over instruction-cue ISI. There is also no visible indication in Fig. 2 that the interaction was likely to reverse had participants been given more time to process the memory instruction.

Although we did not anticipate the pattern of smaller cueing effects after forget instructions than after remember instructions, one might be inclined to invoke a task-switching explanation. When a forget instruction is presented, it signals the need to cease further rehearsal of the most recently presented item (e.g., Hourihan \& Taylor, 2006), and likely prompts a subsequent redirection of processing resources to the retrieval and cumulative rehearsal of previously presented remember items. When a remember instruction is presented, we would argue that there is also a redirection of processing resources due to a shift from maintenance rehearsal to elaborative rehearsal and possibly also due to retrieval and cumulative rehearsal of previously presented remember items (e.g., Rundus, 1971; see also Fawcett \& Taylor, 2008). Even so, we will allow for the possibility that the mental shift is more marked on forget trials than on remember trials because of the need to completely refocus processing resources onto a different item. Granting this assumption, the greater task-switching demands on forget trials may be presumed to compete with the attention cue to reduce its efficacy on forget trials relative to remember trials.

To the extent that unequal task-switching demands on remember and forget trials provides a reasonable framework for explaining our data, we should be able to find evidence that memory instructions interact with other types of taskswitching, such as that which occurs across trials. To test this possibility, we performed a post hoc sorting of Experiment 1 trial data to determine whether each trial repeated the memory instruction from the immediately preceding trial (RememberRemember, Forget-Forget) or switched (Remember-Forget, Forget-Remember). We then included Trial Sequence (Repeat, Switch) as a factor in a re-analysis of the target RT data. This analysis provided weak evidence of overall switch costs, with slightly slower target RTs when memory instructions switched across trials $(M=502 \mathrm{~ms})$ than when they repeated $(M=494 \mathrm{~ms}), F(1,42)=4.52, M S e=2821.31, p<0.04$, ges $<$ $0.01, p \mathrm{H} 1=0.58$. Our data provided weak evidence of larger switch costs on Forget trials $(M=16 \mathrm{~ms})$ than on Remember trials $(M=1 \mathrm{~ms}), F(1,42)=4.03, M S e=2584.17, p>0.05$, ges $<0.01, p \mathrm{H} 1=0.52$. This is consistent with the suggestion that enacting a forget instruction includes a greater element of task switching than does enacting a remember instruction.

Importantly, there were essentially no switch costs on Remember trials $(1 \mathrm{~ms})$, for which some degree of prior-item retrieval and cumulative rehearsal might also have been expected (e.g., Rundus, 1971), even if to a lesser extent than on Forget trials. In this light, the interaction between Memory Instruction and Trial Sequence more likely reflects only the need to withdraw processing resources and stop ongoing covert rehearsal of the current-trial item following a forget instruction but not following a remember instruction (see also Hourihan \& Taylor, 2006; Wylie et al., 2008). In this respect, characterizing the difference between remember and forget instructions as a difference in task-switching demands provides no additional explanatory power over describing forgetting as an active cognitive process. This conclusion is underscored by the finding that all other interactions with Trial Sequence provided positive evidence in support of the null hypothesis: Trial Sequence $\times$ ISI, $F(1,42)<1, M S e=$ $2065.86, p>0.55$, ges $<0.01, p \mathrm{H} 0=0.85$; Trial Sequence $\times$ Cueing Condition, $F(1,42)<1, M S e=2408.36, p>0.44$, ges $<0.01, p \mathrm{H} 0=0.83$; Trial Sequence $\times$ Memory Instruction $\times$ ISI, $F(1,42)<1, M S e=1629.49, p>0.52$, ges $<0.01, p \mathrm{H} 0=$ 0.84 ; Trial Sequence $\times$ Memory Instruction $\times$ Cueing Condition, $F(1,42)<1, M S e=2545.71, p>0.68$, ges $<0.01, p \mathrm{H} 0=$ 0.86 ; Trial Sequence $\times$ ISI $\times$ Cueing Condition, $F(1,42)<1$, $M S e=2835.85, p>0.84$, ges $<0.01, p \mathrm{H} 0=0.87$; and, Trial Sequence $\times$ Memory Instruction $\times$ ISI $\times$ Cueing Condition, $F(1,42)=1.49$, MSe $=2396.39, p>0.22$, ges $<0.01, p \mathrm{H} 0=$ 0.76 . Given that Trial Sequence did not interact with Cueing Condition either alone or in conjunction with Memory Instruction, it seems unlikely that task switching provides a comprehensive framework for interpreting the reduced cueing effect following a forget instruction found in Experiment 1.

Before putting too much reliance on further speculation about our unexpected pattern of smaller cueing effects on forget trials than remember trials, we thought it prudent to ensure that it was not an artifact of our decision to present study words at center. Although presenting the study word at center was a motivated feature of our design, it seems possible in retrospect that presenting all study words at center while all cues and targets were presented in the periphery might have compromised the usual ways in which attention serves the goals of memory. For example, participants might have elected to maintain a fairly diffuse spatial distribution of attention under the assumption that this would maximize the opportunity to detect 
peripheral cues and targets, mistakenly believing that the fovea would "take care of itself" (see Posner, 1980, for discussion of this tendency). It is also possible that presenting the study words at center prompted changes in attention other than differential withdrawal. When words are presented at center, there is no other location equidistant to the cue-target locations and to which attention could retreat post-instruction while still traversing the shortest path. As such, rather than withdrawing attention away from center following a forget instruction, the focus of attention may narrow. This would make the peripheral cues less likely to capture attention following a forget instruction than following a remember instruction and would account for smaller cueing effects following forget instructions than following remember instructions (see also the General Discussion). These concerns suggest the importance of replicating the experiment using a peripheral word presentation before drawing strong conclusions from the observed interaction between memory instruction and cueing.

\section{Experiment 2}

In Experiment 2, the study word appeared with equal probability to the left or right of fixation. As was the case for Experiment 1 , the goal was to determine whether memory instructions interact with the cueing effect to produce a larger cueing effect following forget instructions than following remember instructions.

\section{Method}

\section{Participants}

A total of 46 undergraduate students from Dalhousie University participated in exchange for credit toward an introductory Psychology course. All participants were tested individually in a session that lasted no more than $1 \mathrm{~h}$.

\section{Stimuli and apparatus}

The stimuli and apparatus were identical to those used in Experiment 1.

\section{Procedure}

The procedure was identical to Experiment 1, except that study words were presented with equal probability in the left or right stimulus box. The 160 study trials were thus divided equally and randomly intermixed over all the cells of a 2 (Word Location: Left, Right) $\times 2$ (Memory Instruction: Remember, Forget) $\times 2$ (Instruction-Cue ISI: Short $=50 \mathrm{~ms}$, Long $=250 \mathrm{~ms}) \times 2$ (Cue Location: Left, Right) $\times 2$ (Target
Location: Left, Right) design. For the following analyses, the study data were recast as a 2 (Memory Instruction: Remember, Forget) $\times 2$ (Instruction-Cue ISI: Short $=50 \mathrm{~ms}$, Long $=250$ $\mathrm{ms}) \times 2$ (Cueing Condition: Cued, Uncued) design.

The data analytic strategy was the same as described for Experiment 1.

\section{Results}

Data contributed by three participants were removed from all analyses due to average Foil false alarm rates that were more than 2 SDs above the mean of all participants. There were no data sets excluded based on average target accuracies. The following analyses report the results from the remaining 43 data sets.

\section{Recognition trials}

On the recognition test, there was a mean proportion of 0.65 "yes" responses to Remember words, 0.32 to Forget words, and 0.13 to unstudied Foil words. There was very strong evidence for an effect of Word Type, $F(2,84)=169.65, M S e=$ $0.02, p<0.01$, ges $=0.66, p \mathrm{H} 1>0.99$. A comparison of Remember to Forget trials provided very strong support for a directed forgetting effect, $F(1,42)=135.29, M S e=0.02, p<$ 0.01 , ges $=0.48, p \mathrm{H} 1>0.99$. There was also very strong evidence of more hits to Remember words than false alarms to Foil words, $F(1,42)=214.35, M S e=0.03, p<0.01$, ges $=$ $0.73, p \mathrm{H} 1>0.99$, and very strong evidence of more hits to Forget words than false alarms to Foil words, $F(1,42)=94.17$, $M S e<0.01, p<0.01$, ges $=0.33, p \mathrm{H} 1>0.99$.

As was true for Experiment 1, this pattern of results confirms that participants used the Remember and Forget instructions to selectively encode the words to memory.

\section{Study trials}

The mean proportions of correct responses made within 1001,500 ms of target onset are summarized in Table 1. Across all participants, only 1 trial was excluded for being too fast; all other exclusions were due to erroneous key presses.

Target RTs The mean target RTs on correct study trials are depicted in Fig. 3. The analysis of these data revealed weak evidence against a difference in RTs on Forget and Remember trials, $F(1,42)=2.81, M S e=2198.53, p>0.10$, ges $<0.01$, $p \mathrm{H} 0=0.62$. There was very strong evidence in favor of faster RTs on trials with long Instruction-Cue ISIs compared to trials with short Instruction-Cue ISIs, $F(1,42)=37.06, M S e=$ $1132.22, p<0.01$, ges $=0.02, p \mathrm{H} 1>0.99$. As was the case for Experiment 1, this pattern is consistent with increasing alertness due to decreasing temporal uncertainty (e.g., Nobre et al., 2007). There was also very strong evidence in favor of 
Experiment 2: Peripheral Word, Localization

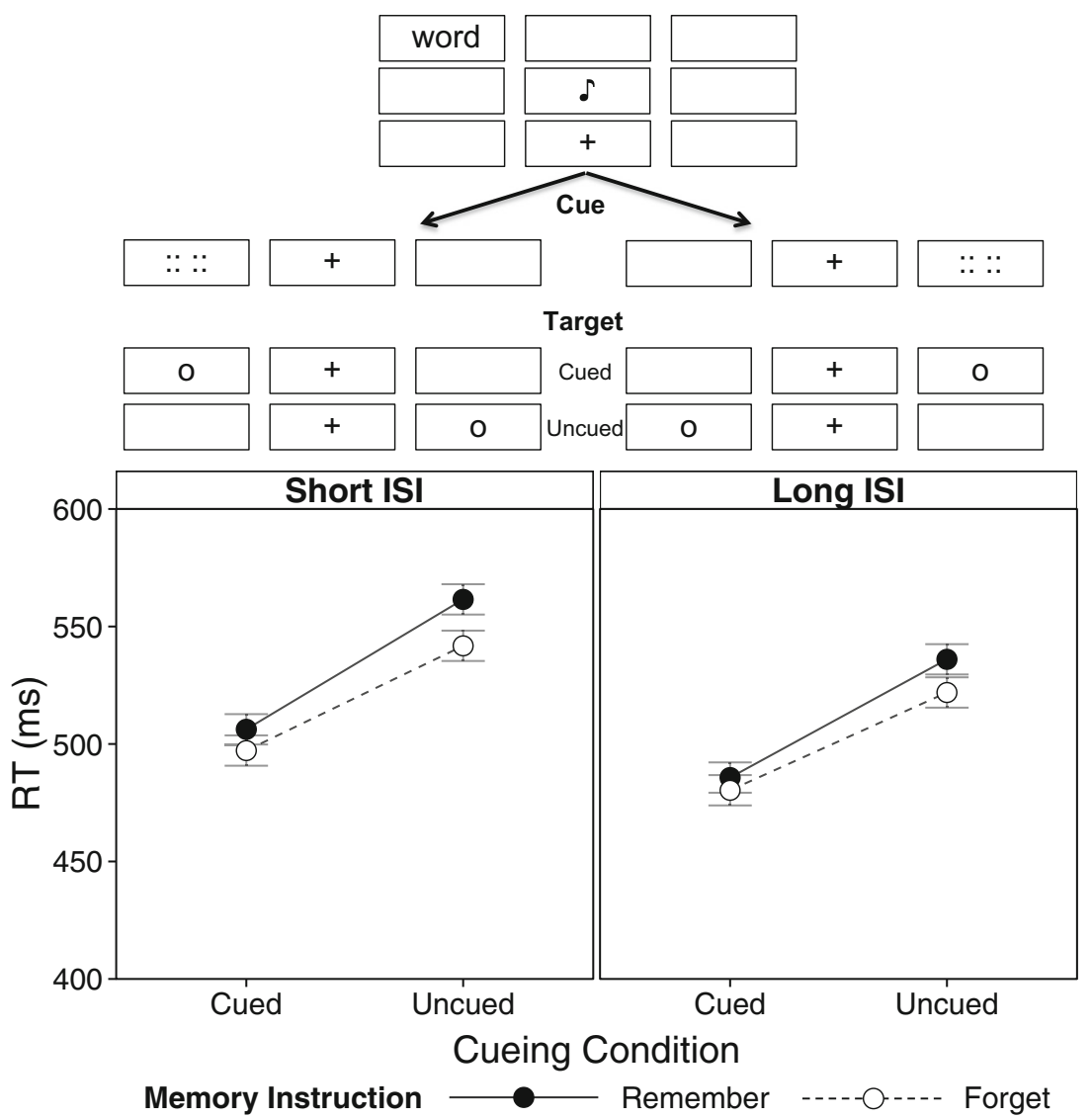

Fig. 3 RTs from study trials of Experiment 2. The top panel depicts possible trial events following a study word to the left; note that in the experiment, study words appeared equally often to the left and right. The bottom panel shows the mean correct RTs (ms) to localize the target as a function of memory instruction (Remember, Forget) and Cueing Condition (Cued, Uncued), separated according to whether the inter-stimulus interval between the Memory Instruction and Cue was relatively Short ( $50 \mathrm{~ms}$, left panel) or Long $(250 \mathrm{~ms}$, right panel). To facilitate visual posthoc comparisons, the error bars represent Fisher's Least Significant Difference on the three-way interaction; non-overlapping bars can be interpreted as being significantly different overall faster RTs to Cued targets $(M=492 \mathrm{~ms})$ than to Uncued targets $(M=540 \mathrm{~ms}), F(1,42)=44.50, M S e=4692.14, p<$ 0.01 , ges $=0.08, p \mathrm{H} 1>0.99$. Thus, again, the cues were effective in capturing attention to the peripheral locations.

There was positive evidence against an interaction between Memory Instruction and Instruction-Cue ISI, $F(1,42)<1, M S e$ $=1486.06, p>0.50$, ges $<0.01, p \mathrm{H} 0=0.84$. For the critical interaction between Memory Instruction and Cueing Condition, the pattern in Fig. 3 appeared to be in the direction opposite that which we predicted, with smaller cueing effects following Forget instructions $(M=43 \mathrm{~ms})$ than following Remember instructions $(M=53 \mathrm{~ms})$. However, the evidence was weakly in favor of the null hypothesis of no interaction, $F(1,42)=2.51, M S e=980.78, p>0.12$, ges $<0.01, p \mathrm{H} 0=$ 0.65 . There was positive evidence against the interaction between ISI and Cueing Condition, $F(1,42)<1, M S e=1609.98$, $p>0.66$, ges $<0.01, p \mathrm{H} 0=0.86$, and against the 3 -way interaction between Memory Instruction, ISI, and Cueing Condition, $F(1,42)<1, M S e=1299.87, p>0.97$, ges $<$
$0.01, p \mathrm{H} 0=0.87$. Thus, there was no evidence that Instruction-Cue ISI modulated a difference in cueing effects on Forget and Remember trials. As was the case for Experiment 1, a visual inspection of Fig. 3 provides no indication that the pattern of cueing effects for Forget and Remember trials was likely to reverse, had participants been given more time to process the instruction.

Target accuracies In a similar fashion, we analyzed the accuracy data summarized in Table 1. There was very strong evidence of more accurate responses to Cued targets $(M=$ $0.98)$ than to Uncued targets $(M=0.92), F(1,42)=46.09$, $M S e=0.01, p<0.01$, ges $=0.25, p \mathrm{H} 1>0.99$. This pattern again counters a speed-accuracy trade-off. There was weak evidence against the interaction between Memory Instruction and Cueing Condition, $F(1,42)=1.59, M S e<0.01, p>0.21$, ges $<0.01, p \mathrm{H} 0=0.75$, and positive evidence against all other main effects and interactions: Memory Instruction, $F(1,42)<$ $1, M S e<0.01, p>0.79$, ges $<0.01, p H 0=0.86$; ISI, $F(1,42)=$ 
$1.26, \mathrm{MSe}<0.01, p>0.26$, ges $<0.01, p \mathrm{H} 0=0.78$; Memory Instruction $\times$ ISI, $F(1,42)<1, M S e<0.01, p>0.50$, ges $<$ $0.01, p \mathrm{H} 0=0.84$; ISI $\times$ Cueing Condition, $F(1,42)<1, M S e<$ $0.01, p>0.96$, ges $<0.01, p \mathrm{H} 0=0.87$; Memory Instruction $\times$ ISI $\times$ Cueing Condition, $F(1,42)<1, M S e<0.01, p>0.85$, ges $<0.01, p \mathrm{H} 0=0.87$.

\section{Discussion}

The results of Experiment 2 again demonstrated that participants used the memory instructions to successfully regulate encoding of study items into long-term memory, as evidenced by a directed forgetting effect. The results also showed that participants' attention was successfully captured by the peripheral onset cues, as evidenced by cueing effects. Although the data pattern in Fig. 3 hints at smaller cueing effects on forget trials than on remember trials, the analysis was against the interaction and revealed weak evidence in support of the null hypothesis of no interaction. Furthermore, only 19 of the 43 participants showed cueing effects in this direction (not a significant number by a Sign Test, $n+=19, n-=24, p>0.54$ ).

Even though the evidence in Experiment 2 countered an interaction between Memory Instruction and Cueing Condition, the pattern of numerically smaller cueing effects on forget trials than on remember trials nevertheless prompted an analysis of task switching. As we had done for Experiment 1, we performed a post hoc sorting of Experiment 2 data according to whether the memory instruction on each trial repeated or switched relative to the preceding trial. Our results mimicked those of Experiment 1. Our data provided weak evidence of switch costs, with average target RTs of $520 \mathrm{~ms}$ on Switch trials and $512 \mathrm{~ms}$ on Repeat trials, $F(1,42)=4.20, M S e$ $=2242.29, p<0.05$, ges $<0.01, p \mathrm{H} 1=0.54$. Our data also provided weak evidence of larger switch costs on Forget trials $(M=16 \mathrm{~ms})$ than on Remember trials $(M=-2 \mathrm{~ms}), F(1,42)=$ 5.90, $M S e=2351.93, p<0.02$, ges $<0.01, p \mathrm{H} 1=0.72$.

As was the case for Experiment 1, we interpret the near- 0 switch costs in the Remember condition as being inconsistent with a role of prior-item retrieval and cumulative rehearsal in the interaction between Memory Instruction and Trial Sequence. It seems more likely that the occurrence of switch costs on forget trials in the context of a relative absence of switch costs on remember trials is related to the need to withdraw processing resources and cease covert rehearsal following a forget instruction but not following a remember instruction (Hourihan \& Taylor, 2006; Wylie et al., 2008). If so, this interaction is reminiscent of the increased probability of successfully stopping unwanted overt responses on forget trials compared to remember trials (Fawcett \& Taylor, 2008). Both interactions point to the engagement of executive control during the implementation of a forget instruction (see Wylie et al., 2008). Even so, as was the case for Experiment 1, there is no evidence that task switching can provide an explanatory framework for the numerical pattern of smaller cueing effects on Forget trials than on Remember trials.

As was also the case for Experiment 1, all other interactions with Trial Sequence provided weak to positive evidence in support of the null hypothesis: Trial Sequence $\times$ ISI, $F(1,42)$ $=2.89, M S e=3152.22, p>0.09$, ges $<0.01, p \mathrm{H} 0=0.61$; Trial Sequence $\times$ Cueing Condition, $F(1,42)=1.93, M S e=$ $1679.67, p>0.17$, ges $<0.01, p \mathrm{H} 0=0.71$; Trial Sequence $\times$ Memory Instruction $\times$ ISI, $F(1,42)<1, M S e=1610.89, p>$ 0.67 , ges $<0.01, p \mathrm{H} 0=0.86$; Trial Sequence $\times$ Memory Instruction $\times$ Cueing Condition, $F(1,42)=2.21, M S e=$ $2140.73, p>0.14$, ges $<0.01, p \mathrm{H} 0=0.69$; Trial Sequence $\times$ ISI $\times$ Cueing Condition, $F(1,42)<1, M S e=2445.00, p>$ 0.61 , ges $<0.01, p \mathrm{H} 0=0.85$; and Trial Sequence $\times$ Memory Instruction $\times$ ISI $\times$ Cueing Condition, $F(1,42)=2.37, M S e=$ $1317.48, p>0.13$, ges $<0.01, p \mathrm{H} 0=0.67$.

This analysis demonstrates that the occurrence and direction of the critical Memory Instruction $\times$ Cueing Condition interaction was not modulated by switch condition. Thus, as we concluded from Experiment 1, it is unlikely that task switching provides a theoretical foundation for understanding how memory intention and attentional capture interact to produce smaller cueing effects on forget trials than on remember trials.

Before discussing these results at greater length, we were motivated to perform one more test of our initial hypothesis that memory instruction would interact with cueing condition to produce larger cueing effects on forget trials than on remember trials. The target tasks in both Experiments 1 and 2 required that participants make a spatially compatible key press to report the location of the target. Thus, cued targets not only occurred in the same location as the cue, they also required a response that was spatially compatible with the cue location; conversely, uncued targets not only occurred in a different location from the cue, they also required a response that was spatially incompatible with the cue location. Irrelevant stimulus information can automatically activate a spatially compatible response code (e.g., Eimer, 1995; Eimer, Hommel, \& Prinz, 1995), providing a means by which our spatial cues might have affected responses directly - along with, or even independently of, attention. If so, an interaction of memory instruction with cueing effects in Experiment 1 (positive evidence in favor) and arguably in Experiment 2 (weak evidence against) might reflect relatively reduced responding following forget instructions rather than relatively reduced attentional orienting. To isolate the effects of memory instructions on attentional orienting, we thus altered the target task in Experiment 3.

\section{Experiment 3}

Experiment 3 replicated the methods of Experiment 2, except that we changed the target task from a spatially compatible 
manual target localization response to a choice manual discrimination response. As such, the manual key-press response to the target no longer reported the location of the target but, instead, reported its identity (see Taylor \& Donnelly, 2002). Although we had initially been reluctant to employ a discrimination response, lest the memory demands of the arbitrary symbol-response mapping prove too challenging in the context of a simultaneous memory task, doing so was necessary in light of the findings of Experiments 1 and 2. The goal was to determine whether we would reproduce the results of Experiment 2 when the target required a more challenging nonspatial manual key-press response.

\section{Method}

\section{Participants}

We initially collected data from 46 undergraduate students at Dalhousie University who participated in exchange for credit toward an introductory psychology course. During debriefing, two of the original participants expressed difficulty with the English language and so we replaced their data with those contributed by two new participants; the culled data were never analyzed. All participants were tested individually in a session that lasted no more than $1 \mathrm{~h}$.

\section{Stimuli and apparatus}

The stimuli and apparatus were identical to those used in Experiment 2 except that the target stimulus consisted of the side-by-side presentation of the forward slash and backslash characters, so that they converged to produce an arrowhead that pointed up $(" \wedge ")$ or down (" $\vee ")$.

\section{Procedure}

The procedure was identical to Experiment 2, except that an additional factor was added to the experimental design: Target Orientation $(U p=" \wedge "$, Down $=" \vee ")$. Half of the participants used the index finger of the left hand on " $\mathrm{f}$ " to report an upward target orientation and the index finger of the right hand on " $\mathrm{j}$ " to report a downward target orientation; these key designations were reversed for the other half of the participants. The 160 study trials were divided equally and randomly intermixed over all the cells of a 2 (Word Location: Left, Right) $\times 2$ (Memory Instruction: Remember, Forget $) \times 2$ (Instruction-Cue ISI: Short $=50 \mathrm{~ms}$, Long $=250 \mathrm{~ms}) \times 2(\mathrm{Cue}$ Location: Left, Right $) \times 2$ (Target Location: Left, Right $) \times 2$ (Target Orientation: Up, Down) design. For the following analyses, the data from Experiment 3 were recast to have the same factor structure as described for Experiment 2: 2 (Memory Instruction: Remember, Forget) $\times 2$ (Instruction-Cue ISI:
Short $=50 \mathrm{~ms}$, Long $=250 \mathrm{~ms}) \times 2$ (Cueing Condition: Cued, Uncued). Notably, half of all trials in each cell of this design required a key-press response that was spatially compatible with the location of the discrimination target and half required a key-press response that was spatially incompatible with the location of the discrimination target. In this way, we controlled for any effects of target-response spatial compatibility.

\section{Results}

Data contributed by two participants were removed from the analyses due to an average false alarm rate to Foil words that exceeded two SDs of the mean of all participants; data contributed by a third participant were removed due to an average target accuracy that was less than 2 SDs of the mean of all participants. The following analyses report the results from the 43 remaining data sets.

Recognition trials There was a mean proportion of 0.61 "yes" responses to Remember words, 0.30 to Forget words, and 0.10 to unstudied Foil words. There was very strong evidence for an effect of Word Type, $F(2,84)=211.97$, MSe = $0.01, p<0.01$, ges $=0.72, p \mathrm{H} 1>0.99$. There was very strong evidence of a directed forgetting effect, as revealed by a comparison of Remember trials to Forget trials, $F(1,42)=135.76$, $M S e=0.01, p<0.01$, ges $=0.52, p \mathrm{H} 1>0.99$. There was also very strong evidence of more hits to Remember words than false alarms to Foil words, $F(1,42)=294.80, M S e=0.02, p<$ 0.01 , ges $=0.79, p \mathrm{H} 1>0.99$, and very strong evidence of more hits to Forget words than false alarms to Foil words, $F(1,42)=142.18$, MSe $=0.01, p<0.01$, ges $=0.46, p \mathrm{H} 1>$ 0.99 .

These results again demonstrate that participants used the Remember and Forget instructions to exert control over encoding of words into long-term memory.

Study trials The proportions of correct responses made within 100-1,500 ms of target onset are summarized in Table 1 . Across all participants a total of only four trials were removed from the analysis due to RTs that were too fast; all other excluded trials reflected incorrect key presses.

Target RTs The mean RTs on correct trials are shown in Fig. 4. An analysis of these data revealed only weak evidence of faster RTs on Forget trials ( $M=707 \mathrm{~ms}$ ) than on Remember trials $(M=722 \mathrm{~ms}), F(1,42)=4.06, M S e=3957.94, p>0.05$, ges $<0.01, p \mathrm{H} 1=0.53$. There was positive evidence against an effect of ISI, $F(1,42)<1, M S e=4499.96, p>0.78$, ges $<$ $0.01, p \mathrm{H} 0=0.86$, likely due to dissipation of alerting effects by the time the discrimination responses were executed. Nevertheless, there was positive evidence for an effect of Cueing Condition, $F(1,42)=8.06$, MSe $=6844.68, p<0.01$, ges $<=$ $0.01, p \mathrm{H} 1=0.87$. This can be seen in Fig. 4 as overall faster 


\section{Experiment 3: Peripheral Word, Discrimination}

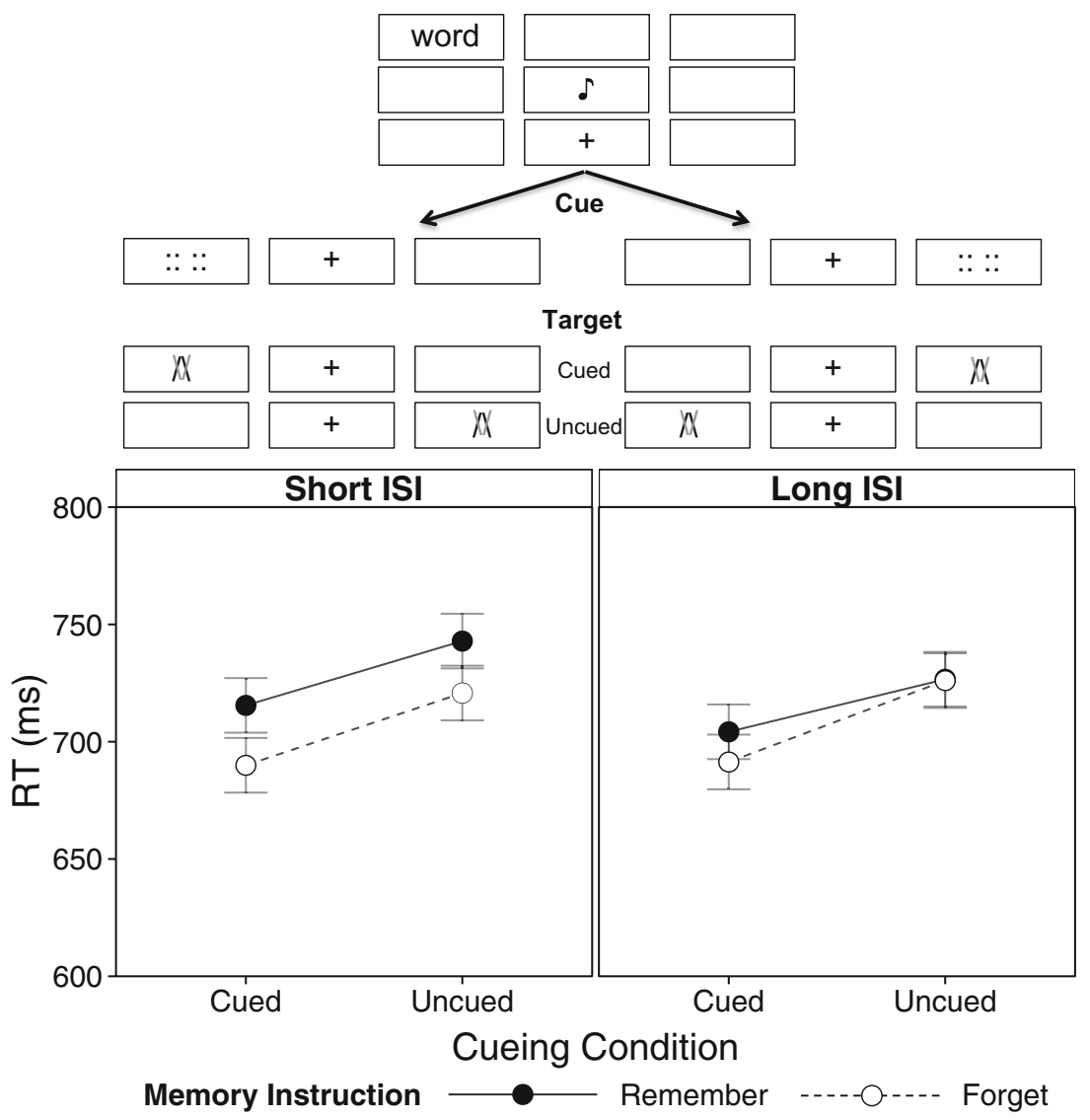

Fig. 4 RTs from the study trials of Experiment 3. The top panel depicts possible trial events following a study word to the left; note that in the experiment, study words appeared equally often to the left and right. Participants responded to the targets in Experiment 3 by indicating whether the single target presented on each trial pointed up or down (both types of target are depicted simultaneusly in this figure). The bottom panel shows the mean correct RTs (ms) to discriminate the target as a function of memory instruction (Remember, Forget) and Cueing Condition (Cued, Uncued), separated according to whether the interstimulus interval between the Memory Instruction and Cue was relatively Short (50 ms, left panel) or Long (250 ms, right panel). To facilitate visual post-hoc comparisons, the error bars represent Fisher's Least Significant Difference on the three-way interaction; non-overlapping bars can be interpreted as being significantly different
RTs to Cued targets $(M=700 \mathrm{~ms})$ than to Uncued targets $(M=$ $729 \mathrm{~ms})$.

There was weak evidence against an interaction between Memory Instruction and Instruction-Cue ISI, $F(1,42)=1.86$, $M S e=3503.50, p>0.18$, ges $<0.01, p \mathrm{H} 0=0.72$. And, importantly, there was positive evidence against the critical interaction between Memory Instruction and Cueing Condition, $F(1,42)<1, M S e=3079.26, p>0.35$, ges $<0.01, p \mathrm{H} 0=$ 0.81 ; the numerically larger cueing effect on Forget trials $(M=$ $33 \mathrm{~ms})$ than on Remember trials $(M=25 \mathrm{~ms})$ was not strong enough to drive an overall interaction. And, there was positive evidence against the interaction of Instruction-Cue ISI and Cueing Condition, $F(1,42)<1, M S e=3237.40, p>0.76$, ges $<0.01, p \mathrm{H} 0=0.86$, as well as against the 3 -way interaction that is intimated in Fig. 4, $F(1,42)<1, M S e=4045.51, p$ $>0.88$, ges $<0.01, p \mathrm{H} 0=0.87$. Thus, there was evidence that the cues were effective in capturing attention to the peripheral locations, but no compelling evidence that the magnitude of the cueing effects on Forget and Remember trials differed under any circumstances tested.

Target accuracies The mean proportions of trials on which a correct key press was made within the specified time window are shown in Table 1. There was weak evidence against an effect of Memory Instruction on target accuracies, $F(1,42)=$ $3.07, M S e=0.01, p>0.08$, ges $=0.01, p \mathrm{H} 0=0.59$, and weak evidence against an effect of Instruction-Cue ISI, $F(1,42)=$ $2.46, M S e=0.01, p>0.11$, ges $<0.01, p \mathrm{H} 0=0.66$. There was, however, very strong evidence in favor of an effect of Cueing Condition on the accuracy of discriminating target identities, $F(1,42)=23.85, M S e=0.01, p<0.01$, ges $=0.04, p \mathrm{H} 1>0.99$. Countering a speed-accuracy trade-off, this effect was due to higher accuracies for responses made to Cued targets $(M=$ $0.78)$ than to Uncued targets $(M=0.72)$. Thus, responses were both faster and more accurate to Cued targets than to Uncued targets. 
There was positive evidence of an interaction between Memory Instruction and Instruction-Cue ISI, $F(1,42)=6.28$, $M S e=0.01, p<0.02$, ges $<0.01, p H 1=0.75$. This stems from the fact that target accuracies on Remember trials were equivalent at the short and long ISIs (both $M \mathrm{~s}=0.74$ ) but that target accuracies on Forget trials were a little higher at the short ISI $(M=0.78)$ than at the long ISI $(M=0.75)$. Because responses on Forget trials tended to be both slower and more accurate at the short ISIs than at the long ISIs, this finding hints at a potential speed-accuracy trade-off. However, the evidence from the target RT analysis was weakly against an interaction between Memory Instruction and Instruction-Cue ISI. Thus, any additional care that participants might have taken to ensure accuracy of their Forget trial responses was not enough to provoke a reliable change in RT. There was positive evidence against all other interactions: Memory Instruction $\times$ Cueing Condition, $F(1,42)<1, M S e=0.01, p>0.52$, ges $<0.01, p \mathrm{H} 0$ $=0.84$; Instruction-Cue ISI $\times$ Cueing Condition, $F(1,42)<1$, $M S e=0.01, p>0.73$, ges $<0.01, p \mathrm{H} 0=0.86$; and, the 3-way interaction of Memory Instruction $\times$ Instruction-Cue ISI $\times$ Cueing Condition, $F(1,42)<1, M S e=0.01, p>0.78$, ges $<$ $0.01, p \mathrm{H} 0=0.86$.

\section{Discussion}

As was true for Experiments 1 and 2, the analysis of the recognition data provided very strong evidence of a directed forgetting effect, suggesting that participants were able to use the memory instructions to exert top-down control over encoding. The increased difficulty of the identity discrimination task compared to the localization tasks of Experiments 1 and 2 was demonstrated by both the longer overall RTs (compare Fig. 4 to Figs. 2 and 3) and by the overall reduced target accuracies (see Table 1). However, performance on the memory task did not seem to suffer as a result of having to do the more difficult target task at the same time as studying words for the later memory test; the overall hit and false alarm rates were comparable across all three experiments. Indeed, if we correct for different rates of guessing by subtracting the Foil false alarms for each experiment from the corresponding Remember and Forget trial recognition hit rates (see Lockhart, 2000), the corrected hit rates across Experiments 1-3, respectively, were: $0.54,0.51$, and 0.51 for Remember words and $0.15,0.19$, and 0.20 for Forget words. Given that compliance with Forget instructions tends to improve with increased demands on limited-capacity resources, the comparability of Forget trial performance across Experiments 2 and 3 argues that the arbitrary symbol-response mapping required for the target discrimination did not increase capacity demands beyond those needed to perform target localization. Thus, despite our initial reservations, the arbitrary symbol-response mapping of the discrimination task did not appear to alter overall memory task performance.

In Experiment 3, there continued to be a very strong and robust cueing effect, with faster and more accurate responses to cued targets than to uncued targets. This demonstrates that the effectiveness of the cues was undiminished by the more difficult target task and underscores the ability of our discrimination targets to measure the impact of those cues on attention. Numerically, the magnitude of the observed cueing effects appeared to differ in the predicted direction, with larger overall cueing effects following Forget instructions $(M=33$ $\mathrm{ms}$ ) than following Remember instructions ( $M=25 \mathrm{~ms})$. Even so, the evidence was antithetical to this conclusion by virtue of being positively supportive of the null hypothesis. Consider this result in context: Experiment 1 provided positive evidence of a difference in the opposite direction to that which we predicted; Experiment 2 provided weak evidence in support of the null hypothesis of no difference; and, Experiment 3 provided positive evidence in support of the null hypothesis of no difference. Whatever the reason for the discrepant patterns across experiment, none of the three experiments offered compelling support for our original hypothesis. Our conclusion thus seems clear: contrary to our initial supposition, attention is not captured more readily following instructions to forget than following instructions to remember.

\section{General discussion}

An instruction to intentionally forget initiates a cognitively effortful (Cheng et al., 2012; Fawcett \& Taylor, 2008; Fawcett et al., 2013a; Lee \& Hsu, 2013) attempt to prohibit further unwanted rehearsal (Hourihan \& Taylor, 2006), through a withdrawal of attentional resources (Fawcett \& Taylor, 2010; Fawcett \& Taylor, 2012; Taylor, 2005; Taylor \& Fawcett, 2011) from the representation of the unwanted item - including its location (Hourihan et al., 2007). In this way, forget items receive less elaboration than remember items and are therefore later remembered with a lower probability and with poorer fidelity (Fawcett et al., submitted), thus accounting for the observed directed forgetting effect in recognition memory. Our question was whether the tendency for attention to withdraw more readily following forget instructions than following remember instructions results in a greater susceptibility to capture and distraction by task-irrelevant changes in the visual environment that occur shortly thereafter.

Across three experiments, we demonstrated robust directed forgetting effects, testifying to the efficacy of our instructions in encouraging control over encoding mechanisms. We also consistently observed robust cueing effects during the study trials, establishing the ability of our onset cues to capture attention even though they themselves required no response and were non-predictive of the location or identity of the 
subsequent target (see also Jonides, 1981; Jonides \& Yantis, 1988; Yantis \& Jonides, 1984). Whereas we expected that cueing effects might be larger following forget instructions than following remember instructions, Experiment 1 provided positive evidence that the cueing effects were, in fact, smaller following forget instructions than following remember instructions. Experiment 2 showed a data pattern that was numerically in the same direction as in Experiment 1, but weakly supportive of the null hypothesis of no difference. The results of Experiment 3 directly countered an interaction of memory instruction and cueing effects by providing positive evidence in support of the null hypothesis.

Notwithstanding the different pattern of results across experiments, the findings are conclusive: the purported withdrawal of attention from forget-item processing does not make attention more vulnerable to subsequent capture in the early intervals following the instruction. This conclusion is important because it demonstrates that attention operates in the service of memory without necessarily being subject to downstream effects as a result of this involvement. Whereas attention withdraws from forget items to limit their further processing and in so doing - reduces processing of other information presented in close temporal and/or spatial proximity (Fawcett \& Taylor, 2008; Fawcett \& Taylor, 2012; Lee \& Hsu, 2013), there is no evidence provided in this study that instantiating a memory instruction sets the stage for an increased susceptibility to distraction by subsequent onset events that capture attention automatically. If anything, attention was less subject to distraction by subsequent events that followed a forget instruction rather than a remember instruction - but only when study words were presented centrally. This surprising finding contradicts our original hypothesis but nevertheless hints at a potential influence of study word location in determining whether and how the implementation of a memory instruction at encoding affects subsequent attentional capture.

\section{The influence of study word location}

Experiments 1 and 2 differed only in the placement of the study word. As such, to determine whether study word location modulated the interaction between memory instruction and attentional cueing, we re-analyzed the data from Experiments 1 and 2 with Experiment as a between-subjects factor. This analysis demonstrated weak evidence in favor of an interaction of Experiment with Memory Instruction and Cueing Condition, $F(1,84)=5.46, M S e=740.41, p<0.03$, ges $<0.01$, $p \mathrm{H} 1=0.62$. This finding supports the conclusion that Experiment 2 did, in fact, produce a different result than Experiment 1 on the critical interaction, consistent with our interim conclusions. When words were presented centrally in Experiment 1 , the magnitude of cueing effects differed as a function of memory instruction - but in a direction opposite that which we predicted. In contrast, when words were presented peripherally in Experiment 2, there was no evidence to support a difference in cueing effects as a function of memory instruction, despite a numerical pattern that appeared similar to Experiment 1. The argument is thus that memory instruction interacts with attentional cueing (even if in the direction opposite our prediction) when study items are presented at center but not when they are presented peripherally. To further confirm this, we compared the results of Experiment 1 (central study words) to the combined data from Experiments 2 and 3 (peripheral study words), with Study Word Location (Central, Peripheral) as a between-subjects factor. This analysis provided positive evidence that the critical interaction between Memory Instruction and Cue Condition differed according to Study Word Location, $F(1,127)=8.93, M S e=1274.35, p$ $<0.01$, ges $<0.01, p \mathrm{H} 1=0.88$.

If one were to assume that participants adopted an attentional control setting that placed the study words in the primary focus of attention, it would follow that peripheral cues and targets were more likely to be outside of this primary attentional focus in Experiment 1 than in Experiments 2 and 3. Under this view, positive evidence of smaller cueing effects following instructions to forget than following instructions to remember in Experiment 1 but not in Experiments 2 and 3 could reflect the modulation of attentional control settings (e.g., Ishigami, Hamm, Satel, \& Klein, 2012). The reasoning is that an instruction to forget a centrally presented word alters the attentional control setting for the experiment, such that the primary attentional focus encompasses less of the visual periphery. This makes attention less vulnerable to capture by peripheral cues. If so, intentional forgetting might not necessarily trigger attentional withdrawal, but attentional narrowing to thus interact with the attentional control setting that is established by the central word presentation. As we have already noted, when study words are presented centrally, there is no suitable place to which attention could withdraw and still be equidistant to both potential target locations while also traversing the shortest path; as such, it seems reasonable that attentional narrowing might be employed as a means of restricting further processing of forget-instructed study items.

The notion that attention is focused on the central location to the relative exclusion of the peripheral locations in Experiment 1 but not in Experiment 2 (which was otherwise identical) appears, at first blush, to be at odds with the overall pattern of target RTs. If participants adopted an attentional control setting that narrowed the focus of attention on centrally presented study words to the relative exclusion of the more peripheral locations (i.e., with even greater narrowing following a forget instruction), one might expect this to be evinced as overall longer target RTs in Experiment 1 compared to Experiment 2. However, the RTs were overall shorter in Experiment 1 than in Experiment 2 and also shorter for both cued and uncued targets. One interpretation is that these data are inconsistent with an interaction of memory instruction with an 
attentional control setting that filters peripheral locations during central word presentation. However, it is also possible that the overall RTs are not a good index of the attentional control setting, due to differences in the oculomotor states across the two experiments. In Experiment 1, the central presentation of study words might have resulted in a more quiescent oculomotor state than the peripheral presentation of study words in Experiment 2, independent of any effects on attentional control setting. As a result, the peripheral target onset might have encouraged a greater tendency to fixation in Experiment 2 than in Experiment 1, thus rendering a direct comparison of overall RTs a poor proxy for inferring attentional control settings. This means that a postulated interaction of memory instruction with attentional control settings (rather than with attention per se) remains a viable post hoc explanation for the smaller cueing effects that were obtained following forget instructions than following remember instructions in Experiment 1 only. This seems a hypothesis worthy of future investigation.

\section{The influence of target task}

Experiments 2 and 3 differed only in the nature of the target task. In neither experiment was there evidence to support the critical interaction of memory instruction and cueing - despite a numerical data pattern in Experiment 2 that seemed to echo that of Experiment 1. When we re-analyzed the data from Experiments 2 and 3 with Experiment as a between-subjects factor, weak evidence in favor of the null hypothesis was consistent with our interim conclusion that these experiments produced similar results on the critical interaction, $F(1,84)=2.29, M S e=$ $1447.36, p>0.13, p \mathrm{H} 0=0.74$. This finding argues that target task is not a critical determinant of whether and how attentional cueing effects are modulated by memory instruction.

This null result is important because it converges with recent evidence that argues against an influence of memory instruction on the automatic activation of a spatially compatible response code by the cue (see Thompson et al., 2014; Thompson $\&$ Taylor, 2015). Indeed, if a forget instruction had weakened spatial code activation by the cue onset (e.g., Taylor \& Fawcett, 2011), this would have been evident in subsequent target RTs any time a localization response was required, such as used in Experiment 1 (for which there was evidence of smaller cueing effects following forget instructions than remember instructions) and in Experiment 2 (for which there was a numerical pattern but no support for smaller cueing effects following forget instructions than remember instructions).

To provide further argument against the notion that target localization was critical to finding an effect of memory instruction on attentional cueing, we repeated our analysis of the Experiment 3 target RTs using only those trials that required a key-press response that happened to be spatially compatible with the location of the target (e.g. " $\mathrm{f}$ " to discriminate a target on the left and " $\mathrm{j}$ " to discriminate a target on the right). If a forget instruction decreases the automatic activation of a spatial code relative to a remember instruction, then subsequent responses to targets in the cued location versus uncued location should reveal this influence in the restricted analysis, viz. smaller cueing effects on forget trials than on remember trials (to correspond with the results of the Experiment 1 localization task and the numerical pattern of interaction in the localization task of Experiment 2). This prediction was not borne out in our data. When we considered only target discrimination trials that required a spatially compatible response to identify the target orientation, the data provided positive evidence in favor of the null hypothesis of no interaction between Memory Instruction and Cueing Condition, $F(1,42)<1, M S e=1976.80, p>0.91$, ges $<0.01, p \mathrm{H} 0=$ 0.87 . This finding provides further evidence against an effect of memory instruction on spatial code activation by the cue (see also Thompson et al., 2014) and argues against target task being an important determinant of whether and how memory intentions formed at encoding interact with subsequent attentional capture.

\section{Effects of attentional capture on intentional forgetting}

The preceding analyses provide some tantalizing post hoc evidence that study word location might be a key variable in determining whether and how attentional cueing effects are influenced by memory intentions. Nevertheless, the fact remains that any such changes in attention by a memory instruction were in a direction opposite that which we had predicted. This led us to one final consideration. Rather than memory intention modulating attentional capture as we have presumed, perhaps attentional capture modulates the success of the memory intention. To the extent that spatial location forms part of the stored memory representation for peripherally presented study words (see Hourihan et al., 2007), it might be reasonable to presume that the capture of attention to the location of a studied word bolsters the encoding of that item - fortifying an intention to remember and subverting an intention to forget.

To test this, we determined whether attentional capture following a peripheral study word influenced the success of subsequent recognition. Performing separate analyses on the data from Experiments 2 and 3 (which both presented peripheral study words and thus included spatial information in the word representation), we examined the proportion of recognition hits as a function of study conditions - Memory Instruction (Remember, Forget), Word-Cue Location (Same, Different), and Cueing Condition (Cued, Uncued). The data from both experiments provided positive evidence against an effect of Word-Cue Location, against an effect of Cueing Condition, and against all interactions that included these factors, all $F_{\mathrm{S}}<$ 1 , all $p \mathrm{H} 0>0.80$. This counters the suggestion that attention might have influenced the instantiation of the memory 
instruction, rather than vice versa. Thus, in general, memory instruction does not reliably determine vulnerability of attention to capture by subsequent events and - conversely - the capture of attention by subsequent events does not dictate the outcome of the memory intention.

\section{Conclusion}

Attention operates in the service of memory to remove limited-capacity processing resources from further processing of unwanted forget items (e.g., Taylor, 2005; Taylor \& Fawcett, 2011; Wylie et al., 2008) as well as from other items presented in close spatial and/or temporal proximity (e.g., Fawcett \& Taylor, 2008; Fawcett \& Taylor, 2012; Lee \& Hsu, 2013). The results of the current investigation demonstrate that the removal of attention from a forget item representation is a time-limited operation linked directly to the memory intention formed at encoding; it does not result in a longer-term change in the vulnerability of attentional resources to capture by subsequent events. Indeed, the results of all three experiments converged on the conclusion that our original hypothesis was wrong: the removal of attention from a forget-item representation does not make attention more vulnerable to capture by subsequent events that occur shortly thereafter.

This finding represents an important constraint on the influence that memory intentions have on the allocation of attentional resources. Instantiating intentions to remember and forget marshals support from the attentional system to ensure that limited-capacity resources are directed to the rehearsal of remember-instructed items, not wasted on needless rehearsal of forget-instructed items. Our results suggest that the allocation of attentional resources according to encoding strategies is under fine control: the intention to remember or forget influences only the immediate allocation of attentional resources. Indeed, even after a very short delay following the disappearance of a memory instruction (i.e., the $50 \mathrm{~ms}$ instruction-cue ISI), visual attention is responsive to visual onset events. Accordingly, despite the effortful nature of intentional forgetting (Cheng et al., 2012; Lee \& Hsu, 2013; Ludowig et al., 2010; Fawcett \& Taylor, 2008; Fawcett et al., 2013a), attention remains alert to transient changes in the environment. The only exception seems to be when attentional control settings are used to limit the active monitoring of peripheral visual locations. In this instance, instructions to forget may cause a narrowing of attention that interacts with the control setting to reduce the responsiveness of the attentional system to visual transients. Although these conclusions are not what we anticipated from the start, they do speak to the critical role that attention plays in striking a balance between the need to maintain focused goal-directed activity and the need to monitor the environment for sudden changes that might demand reprioritization of this activity.

Author note Thanks to Jonathan Fawcett for providing the custom software used to randomize and distribute the word stimuli and to Tom Howells and Kate Thompson for collecting the data. Thanks to Drs. Colin MacLeod, Michael Masson, and an anonymous reviewer for very helpful comments on earlier versions of this manuscript. Thanks also to our participants for volunteering their time and effort to contribute data toward this project. Funding was provided by a Discovery Grant awarded to TLT from the Natural Sciences and Engineering Research Council of Canada.

\section{References}

Anderson, M. C. (2003). Rethinking interference theory: Executive control and the mechanisms of forgetting. Journal of Memory and Language, 49(4), 415-445.

Anderson, M. C., \& Huddleston, E. (2012). Towards a cognitive and neurobiological model of motivated forgetting. In R. F. Belli (Ed.), True and False Recovered Memories: Toward a Reconciliation of the Debate (pp. 53-120). New York: Springer New York.

Aron, A. R., Fletcher, P. C., Bullmore, E. T., Sahakian, B. J., \& Robbins, T. W. (2003). Stop-signal inhibition disrupted by damage to right inferior frontal gyrus in humans. Nature Neuroscience, 6(2), 115116.

Basden, B. H. (1996). Directed forgetting: Further comparisons of the item and list methods. Memory, 4(6), 633-654.

Basden, B. H., Basden, D. R., \& Gargano, G. J. (1993). Directed forgetting in implicit and explicit memory tests: A comparison of methods. Journal of Experimental Psychology: Learning, Memory, and Cognition, 19(3), 603-616.

Bjork, R. A. (1970). Positive forgetting: The noninterference of items intentionally forgotten. Journal of Verbal Learning and Verbal Behavior, 9(3), 255-268.

Bjork, R. A. (1989). Retrieval inhibition as an adaptive mechanism in human memory. In H. L. Roediger III \& F. I. M. Craik (Eds.), Varieties of memory and consciousness (pp. 309-330). Hillsdale: Erlbaum.

Cheng, S. K., Liu, I. C., Lee, J. R., Hung, D. L., \& Tzeng, O. J. L. (2012). Intentional forgetting might be more effortful than remembering: An ERP study of item-method directed forgetting. Biological Psychology, 89(2), 283-292.

Cohen, J. D., MacWhinney, B., Flatt, M., \& Provost, J. (1993). PsyScope: A new graphic interactive environment for designing psychology experiments. Behavioral Research Methods, Instruments, and Computers, 25, 257-271.

Coltheart, M. (1981). The MRC Psycholinguistic Database. Quarterly Journal of Experimental Psychology, 33A, 497-505.

Eimer, M. (1995). Stimulus-response compatibility and automatic response activation: Evidence from psychophysiological studies. Journal of Experimental Psychology: Human Perception and Performance, 21(4), 837-854.

Eimer, M., Hommel, B., \& Prinz, W. (1995). SR compatibility and response selection. Acta Psychologica, 90(1), 301-313.

Fawcett, J. M., \& Taylor, T. L. (2008). Forgetting is effortful: Evidence from reaction time probes in an item-method directed forgetting task. Memory \& Cognition, 36(6), 1168-1181.

Fawcett, J. M., \& Taylor, T. L. (2010). Directed forgetting shares mechanisms with attentional withdrawal but not with stop-signal inhibition. Memory \& Cognition, 38(6), 797-808. 
Fawcett, J. M., \& Taylor, T. L. (2012). The control of working memory resources in intentional forgetting: Evidence from incidental probe word recognition. Acta Psychologica, 139(1), 84-90.

Fawcett, J. M., Taylor, T. L., \& Nadel, L. (2013a). Event-method directed forgetting: Forgetting a video segment is more effortful than remembering it. Acta Psychologica, 144(2), 332-343.

Fawcett, J. M., Taylor, T. L., \& Nadel, L. (2013b). Intentional forgetting diminishes memory for continuous events. Memory, 21(6), 675694.

Gardiner, J. M., Gawlik, B., \& Richardson-Klavehn, A. (1994). Maintenance rehearsal affects knowing, not remembering: Elaborative rehearsal affects remembering, not knowing. Psychonomic Bulletin \& Review, 1(1), 107-110.

Hawkins, H. L., Hillyard, S. A., Luck, S. J., Mouloua, M., Downing, C. J., \& Woodward, D. P. (1990). Visual attention modulates signal detectability. Journal of Experimental Psychology: Human Perception and Performance, 16(4), 802-811.

Hopfinger, J. B., \& Mangun, G. R. (1998). Reflexive attention modulates processing of visual stimuli in human extrastriate cortex. Psychological Science, 9(6), 441-447.

Hopfinger, J. B., \& Mangun, G. R. (2001). Tracking the influence of reflexive attention on sensory and cognitive processing. Cognitive, Affective, \& Behavioral Neuroscience, 1(1), 56-65.

Hourihan, K. L., \& Taylor, T. L. (2006). Cease remembering: Control processes in directed forgetting. Journal of Experimental Psychology: Human Perception and Performance, 32(6), 13541365.

Hourihan, K. L., Goldberg, S., \& Taylor, T. L. (2007). The role of spatial location in remembering and forgetting peripheral words. Canadian Journal of Experimental Psychology, 61(2), 91-101.

Hsieh, L. T., Hung, D. L., Tzeng, O. J. L., Lee, J. R., \& Cheng, S. K. (2009). An event-related potential investigation of the processing of Remember/Forget cues and item encoding in item-method directed forgetting. Brain Research, 1250, 190-201.

Ishigami, Y., Hamm, J. P., Satel, J., \& Klein, R. M. (2012). Exploring the modulation of attentional capture by spatial attentional control settings: Converging evidence from event-related potentials. Experimental Brain Research, 223(4), 525-532.

Johnson, H. M. (1994). Processes of successful intentional forgetting. Psychological Bulletin, 116(2), 274.

Jonides, J. (1981). Voluntary versus automatic control over the mind's eye's movement. Attention and Performance IX (pp. 187-203). Hillsdale: Lawrence Erlbaum Associates, Inc.

Jonides, J., \& Yantis, S. (1988). Uniqueness of abrupt visual onset in capturing attention. Perception \& Psychophysics, 43(4), 346-354.

Kucera, H., \& Francis, N. (1967). Computational analysis of present-day American English. Providence: Brown University Press.

Kuhl, B. A., Dudukovic, N. M., Kahn, I., \& Wagner, A. D. (2007). Decreased demands on cognitive control reveal the neural processing benefits of forgetting. Nature Neuroscience, 10(7), 908-914.

Lawrence, M. A. (2013). ez: Easy analysis and visualization of factorial experiments. R package version 4.2-2. http://CRAN.R-project.org/ package $=\mathrm{ez}$

Lee, Y. S. (2012). Cognitive load hypothesis of item-method directed forgetting. The Quarterly Journal of Experimental Psychology, 65(6), 1110-1122.

Lee, Y. S., \& Hsu, Y. C. (2013). How do we forget negative events? The role of attentional, cognitive, and metacognitive control. Cognition \& Emotion, 27(3), 401-415.

Lee, Y. S., \& Lee, H. M. (2011). Divided attention facilitates intentional forgetting: Evidence from item-method directed forgetting. Consciousness and Cognition, 20(3), 618-626.

Lee, Y. S., Lee, H. M., \& Tsai, S. H. (2007). Effects of post-cue interval on intentional forgetting. British Journal of Psychology, 98(2), 257272.
Lee, Y. S., Lee, H. M., \& Fawcett, J. M. (2013). Intentional forgetting reduces color-naming interference: Evidence from item-method directed forgetting. Journal of Experimental Psychology: Learning, Memory, and Cognition, 39(1), 220-236.

Lin, W. J., Kuo, Y. C., Liu, T. L., Han, Y. J., \& Cheng, S. K. (2013). Intentional forgetting reduces the semantic processing of to-be-forgotten items: An ERP study of item-method directed forgetting. Psychophysiology, 50(11), 1120-1132.

Lockhart, R. S. (2000). Methods of memory research. In E. Tulving \& F. I. M. Craik (Eds.), The Oxford Handbook of Memory (pp. 45-57). New York: Oxford University Press.

Ludowig, E., Möller, J., Bien, C. G., Münte, T. F., Elger, C. E., \& Rosburg, T. (2010). Active suppression in the mediotemporal lobe during directed forgetting. Neurobiology of Learning and Memory, 93(3), 352-361.

MacLeod, C. M. (1998). Directed forgetting. In J. M. Golding \& C. M. MacLeod (Eds.), Intentional forgetting: Interdisciplinary approaches (pp. 1-57). Mahwah: Lawrence Erlbaum Associates.

Masson, M. E. (2011). A tutorial on a practical Bayesian alternative to null-hypothesis significance testing. Behavior Research Methods, 43(3), 679-690.

Müller, H. J., \& Rabbitt, P. M. (1989). Reflexive and voluntary orienting of visual attention: Time course of activation and resistance to interruption. Journal of Experimental Psychology: Human Perception and Performance, 15(2), 315-330.

Nobre, A. C., Correa, A., \& Coull, J. T. (2007). The hazards of time. Current Opinion in Neurobiology, 17(4), 465-470.

Paller, K. A. (1990). Recall and stem-completion priming have different electrophysiological correlates and are modified differentially by directed forgetting. Journal of Experimental Psychology: Learning, Memory, and Cognition, 16(6), 1021-1032.

Posner, M. I. (1980). Orienting of attention. Quarterly Journal of Experimental Psychology, 32(1), 3-25.

$\mathrm{R}$ Core Team (2014). R: A language and environment for statistical computing. R Foundation for Statistical Computing, Vienna, Austria. URL http://www.R-project.org/

Raftery, A. E. (1995). Bayesian model selection in social research. Sociological Methodology, 25, 111-164.

Rizio, A. A., \& Dennis, N. A. (2013). The neural correlates of cognitive control: Successful remembering and intentional forgetting. Journal of Cognitive Neuroscience, 25(2), 297-312.

Rundus, D. (1971). Analysis of rehearsal processes in free recall. Journal of Experimental Psychology, 89, 63-77.

Taylor, T. L. (2005). Inhibition of return following instructions to remember and forget. The Quarterly Journal of Experimental Psychology, 58(4), 613-629.

Taylor, T. L., \& Donnelly, M. P. (2002). Inhibition of return for target discriminations: The effect of repeating discriminated and irrelevant stimulus dimensions. Perception \& Psychophysics, 64(2), 292-317.

Taylor, T. L., \& Fawcett, J. M. (2011). Larger IOR effects following forget than following remember instructions depend on exogenous attentional withdrawal and target localization. Attention, Perception, \& Psychophysics, 73(6), 1790-1814.

Thompson, K. M., \& Taylor, T. L. (2015). Memory instruction interacts with both visual and motoric inhibition of return. Attention, Perception, \& Psychophysics, 77(3), 804-818.

Thompson, K. M., Hamm, J. P., \& Taylor, T. L. (2014). Effects of memory instruction on attention and information processing: Further investigation of inhibition of return in item-method directed forgetting. Attention, Perception, \& Psychophysics, 76(2), 322-334.

van Hooff, J. C., \& Ford, R. M. (2011). Remember to forget: ERP evidence for inhibition in an item-method directed forgetting paradigm. Brain Research, 1392, 80-92.

Verbruggen, F., \& Logan, G. D. (2008). Response inhibition in the stopsignal paradigm. Trends in Cognitive Sciences, 12(11), 418-424. 
Wickham, H. (2009). ggplot2: Elegant graphics for data analysis. Springer New York. http:/had.co.nz/ggplot2/book

Wickham, H. (2011). The split-apply-combine strategy for data analysis. Journal of Statistical Software, 40(1), 1-29. http://www.jstatsoft. org/v40/i01/

Wickham, H. (2012). stringr: Make it easier to work with strings. $\mathrm{R}$ package version 0.6.2. http://CRAN.R-project.org/package=stringr

Wickham, H. (2014). tidyr: Easily Tidy Data with spread() and gather() Functions.. R package version 0.2.0. http://CRAN.R-project.org/ package $=$ tidyr

Wickham, H. \& Francois, R. (2014). dplyr: A grammar of data manipulation. $\mathrm{R}$ package version 0.3.0.2. http://CRAN.R-project. org $/$ package $=$ dplyr
Wilson, M. D. (1988). The MRC Psycholinguistic Database: Machine Readable Dictionary, Version 2. Behavioural Research Methods, Instruments and Computers, 20, 6-11.

Wylie, G. R., Foxe, J. J., \& Taylor, T. L. (2008). Forgetting as an active process: An fMRI investigation of item-method-directed forgetting. Cerebral Cortex, 18(3), 670-682.

Yang, W., Liu, P., Xiao, X., Li, X., Zeng, C., Qiu, J., \& Zhang, Q. (2012). Different neural substrates underlying directed forgetting for negative and neutral images: An event-related potential study. Brain Research, 1441, 53-63.

Yantis, S., \& Jonides, J. (1984). Abrupt visual onsets and selective attention: Evidence from visual search. Journal of Experimental Psychology: Human Perception and Performance, 10, 601-621. 